\title{
مدى تطبيق معاوني أعضاء هيئة التدريس لاستراتيجيات التدريس الفعال من وجهه نظر طلاب الاقتصاد المنزلي بكلية التربية النوعية
}

\author{
إعـداد \\ داطمة عبد الرزاق عمر \\ مدرس مناهج وطرق تدريس الاقتصاد المنزلي \\ كلية التربية النوعية بقنا \\ جامعة جنوب الو ادي
}




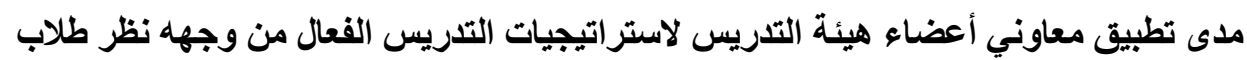
الاقتصاد المنزلي بكلية التربية التورينية التوعية الترين

داطمة عبد الرزاق عمر

\section{ملدى تطيبق معاوذي أعضاء هيئة التلدربس لاستراتيجيات التبدربس}

\section{الثفال مز وجهه ذنر طلاب الاقتمساد المنزلي بكلية التربية النومية د/ فاطمة عبل الرزاق عمر محمد}

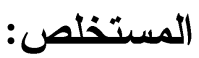

هدفت هذه الدر اسة إلى التعرف على مدى تطبيق معاوني أعضاء هيأـــة التـدريس

بقسم الاقتصاد المنزلي - بكلية التربية النوعيـة - جامعــة جنــوب الوادي،لاســتر اتيجيات التدريس الفعال من وجهه نظر الطلاب ،وقد تكونــت عينــة الدراســة مــن ( . . اطلــب

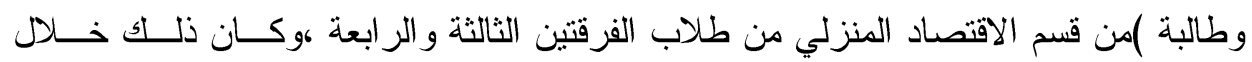

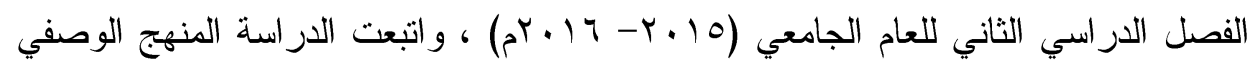
التحليلي ،وقامت الباحثة باستخدام أداة الدراسة وهى عبارة عن استبيان موجه للطلاب .وقــد أثنارت نتائج الدراسة إلى : (1) وجود فروق ذات دلالة إحصائية بين درجات الطلاب فـي الإجابة على الاستبيان ترجع إلى عدم تطبيق معاوني أعضاء هيئة التدريس لخطـــوات كـلـل إستر اتيجية بنفس الدرجة من الكفاءة. (Y) عدم وجود فروق ذات دلالة إحصائية في إجابــات الإبهاء الطلاب على الاستبيان الذي يقيس مدى تطبيق معاوني أعضاء هيئة التذريس لاســتر اتيجيات

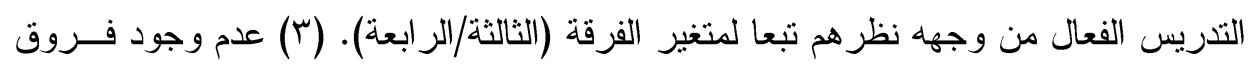
ذات دلالة إحصائية في إجابات الطلاب على الاستبيان بالذي يقيس مــدى تطبيــق معــاوني أعضاء هيئة التذريس الفعال من وجهه نظر هم تبعا لمتغير التخصص (تغذية /ملابس). الكلماث المفتاحية : أهلة استراتيجية ،التدريس الفعال ، الاقتصاد المنزلي ، كلية التزبية النوعية. 
مدى تطبيق معاوني أعضاء هيئة التدريس لاستراتيجيات التدريس الفعال من وجهه نظر طلاب الاقتصاد المنزلي بكلية التربية النوعية الترين

د/فاطمة عبد الرزاق عمر

The range of applying the faculty assistants for strategies

of effective teaching of students of home economics in

Faculty of specift education

\section{Dr. Fatma Abdelrazak Omar}

\section{Abstract :}

This study aimed to identify the extent of the application of the assistants of the members of the teaching staff at the home economics, effective teaching strategies from the face of the students, the study sample consisted of ( $\cdots$ ) of home economics students from the third and fourth grades, the study followed the Descriptive analytical method, researcher using a questionnaire to the students and the result of the study indicated. 1) The existence of statistically significant differences between the scores of students in answering the questionnaire, due to the lack of application of assistants faculy steps each strategy the same degree of effifiency differences. r) There were no statistically significant differences in the students answers, application for effective teaching of their point view depending on the variable of the class. r) There were no statistically significant differences in the students answers which measures the extent of the application of effective teaching assistants staff members from their point of view depending on the specialization.

Keywords: Strategy- eggective teaching - home economics Faculty of specific education 


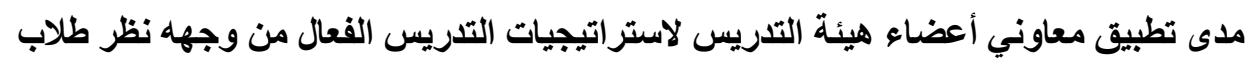
الاقتصاد المنزلي بكلية التربية التورينية التوعية الترين

\section{داطفمة عبد الرزاق عمر}

\section{مقدمة البحث:}

يشهد القرن الواحد و العشرون ثورة معلوماتية وتكنولوجية هائلة فى جميع مجــالات الحياه حتى أصبح تقدم الامم يقاس على أساس ما نأخذ به من أساليب علمية حديثة فى تربية

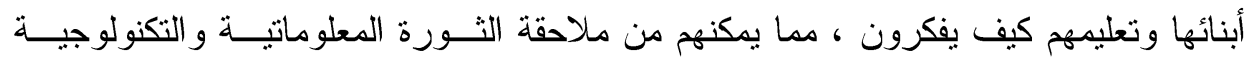
و التكيف مع متطلبات العصر • ( هدى بابطين ، r ا • بم ) . وتعد الجامعات اليوم أحد أهم العناصر اللازمة لبناء حضارة العصر الذى نعيش فيه من خلال أهدافها ووظائفها الأساسية المتمتلة فى التعليم و البحث العلمى وخدمة المجتمع ، حيــث يتوقف عليها حسن توظيف مو اردها البشرية و المادية حتى تتمكن من الوصول الــى مر اكــز

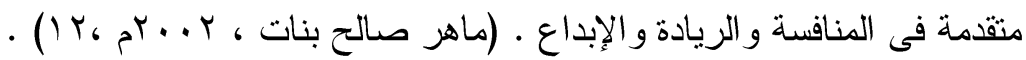
وبما أن الجامعات هى المسئولة عن المخرجات التعليمية فالنظر و التمعن فى هـذهـ المخرجات نجد أن نسبة كبيرة منهم ليست بالمستوى المأمول فى عدة نــو احى مــن حيــث امتلاكهم للمهار ات الأساسية فى القراعة و الكتابة و العلوم و المهار ات بمختلف الفروع و علــى الرغم من الجهود المبذولة من أعضاء هيئة التدريس و المشرفين والادارات التربوية الا أنهـــا

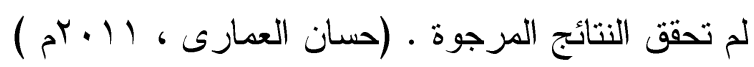
بسبب وجود فجوه بين احتياجات الطلاب وبين قدرات ومهـــار ات أعضـــاء هيءــة التدريس ومعاونيهم ، وبما أن المعلم هو المحور الرئيسى فى بناء العملية التعليمية والقطــب الاساسى فى توجيهها بنشاطه و انتمائه وتفانيه ، ويتم الحكم على نجاحها وفاعليتها بجهد المعلم

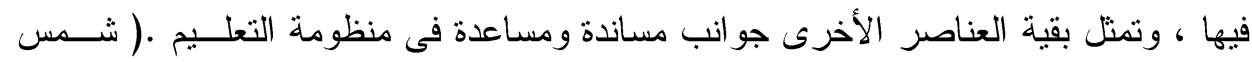

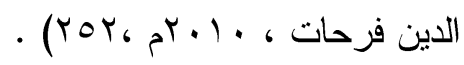

لذلك فأنه على المعلم أن يبذل قصارى جهده للتعرف على و إتقان طرق التـدريس المختلفة ، وما هى الأدوات و الوسائل التى تعينه على أداء درسة بمهارة . و وأن يجد ما ينفعه

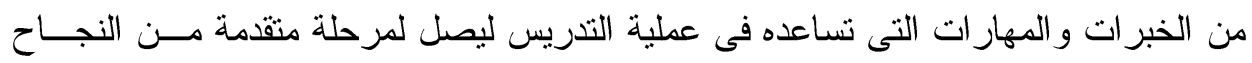
ويو اكب أحدث المجريات العالمية فى المجال التزبوى سواء كانت المو اد التى يقوم بتدريســـها مو اد نظرية أو مو اد عملية كمو اد الاقتصاد المنزلى كالتغذية و الملابس و إدارة المنزل . . وذللك لأن الإستراتيجيات التي يستخدمها عضو هيئة التذريس لها تأثير مهــم علـى تعلم الطلبة ـ و أنه بامكان عضو هيئة التدريس أو معاونه بقليل من التـدريب علــى اتبــاع

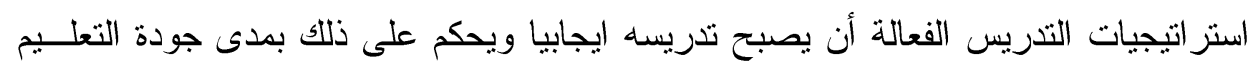

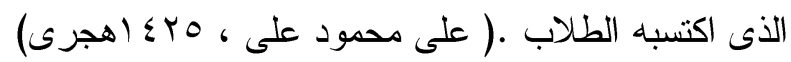




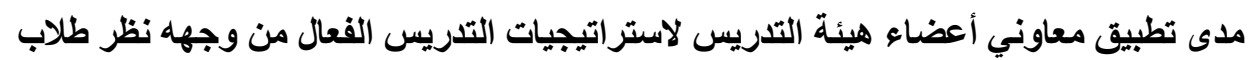
الاقتصاد المنزلي بكلية التربية التورينية التوعية الترين

\section{داطفمة عبد الرزاق عمر}

ومن المهم أن نوضح أن هناك طرق مختلفة للتدريس ، ويمكن تصنيفها الى نوعين

هما طرق تدريس عامة : وهى الطرق التى يحتاج معلمو جميع التخصصات الى استخدامها . طرق تدريس خاصـة : وهى الطرق التى يشيع استخدامها من قبل معلمى تخصص معين ، ويندر استخدامها من قبل معلمى التخصصات الأخرى •وحتى تكون استراتيجيات التدريس التى يستخدمها معاونى أعضاء هيئة التدريس فى مجال الاقتصاد المنزلى التطبيقى فعالة فعليه

$$
\text { مر اعاة أن تكون : }
$$

- شاملة ،بمعنى أنها تتضمن كل المواقف و الاحتمالات المتوقعة .

- - ترتبط ارتباط و اضتح بالأهداف التزبوية و الاجتماعية و الاقتصادية .

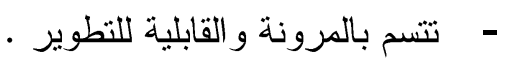

- تكون عالية الكفاءة من حيث مقارنة ما تحتاجه من امكانيات عند التنفيذ مع ما تتتجه

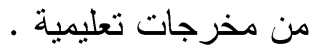

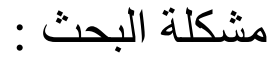

نظر الان المعلم هو المحور الرئيسى فى العملية التعليمية وهــو أحــد المســولين الأساسيين عن جودة المخرجات التعليمية ـ لذلك فأنه من الضرورى على مؤسسات التعلــيم تهيئة كل الظروف لتحسين جودة أداء معاونى أعضاء هيئة التذريس المسئولين عن تـدريس هن المو اد العملية (التطبيقية ) وذلك من خلال عمليات التقويم والتحسين المستمر . كما أن المتعلم ( الطالب الجامعى ) يجب أن يكون له دور فعال فى عملية تعليمــة فيجب أخذ رأية بالاعتبار حتى تتم عملية التدريس بطريقة صــحيحة فـى ضـــوء ميــولهم و احتياجاتهم حتى يتحقق هدف من أهداف التربية وهو تتمية قدراتهم ومســتوياتهم المعرفيــة

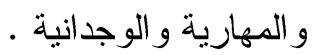
ولقد لاحظت الباحثة من خلال عملها كعضو هيئة تدريس بقسم الاقتصاد المنزلى بكلية التربية النوعية -جامعة جنوب الو ادى ، ومن خلال تفريغ استبيان موجه للطالبات عـن

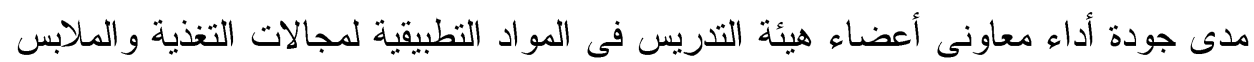
و ادارة المنزل من وجهة نظر الطالبات . مأل فتبين أنه توجد ملاحظات على أداء معاونى هيئة التدريس تمثلت فى التالى : - اعتماد V9\% من معاونى أعضاء هيئة التدريس على استر اتيجية و احدة هى البيات - العملى - عدم مشاركة الطلاب حتى فى البيان العملى · 


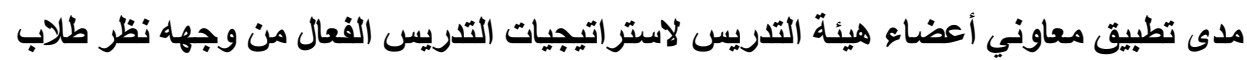
الاقتصاد المنزلي بكلية التربية التورينية التوعية الترين

داطمة عبد الرزاق عمر

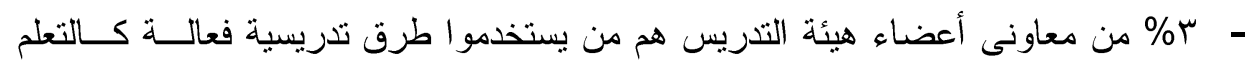

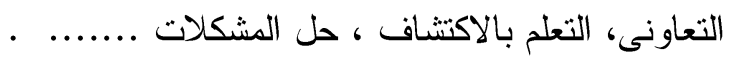

- عدم تفاعل الطلاب مع المادة العلمية نتيجة قصور فى اســتخدام الأســتراتيجيات التـى تساعدهم على التفاعل حتى لو تم استخدام استر اتيجية حديثة قلما يتم تطبيق خطوات التنفيذ

بفاعلية .

من هنا تبلورت مشكلة الدر اسة فى التعرف على فاعلية استخدام معــاونى أعضـــاء

هيئة التذريس لاستراتيجيات التدريس الفعالة فى المواد العملية من وجهه نظر طلبة الأقتصاد

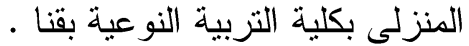

$$
\text { أهداف البحثث : تتحدد أهداف البحث في : }
$$

1- التعرف على مدى استخدام معاوني أعضاء هيئة التدريس لبعض استر اتيجيات

$$
\text { التدريس الفعالة . }
$$

r- توضيح ما إذا كان يتم تطبيق هذه الاستر اتيجيات بالطريقة الصحيحة .

r- وضع الحلول المناسبة لمعاوني أعضاء هيئة التدريس حتى يستطيعو استخدام

استر اتيجيات التدريس بفاعلية عند تدريسهم للمو اد العملية .

$$
\text { أهمبة البحث : ترجع أهمية البحث إلى أنه يساعد في : }
$$

1- تحديد مشكلة هامة من المشكلات التذريسية في المواد العملية بقسم الاقتصاد

$$
\text { - المنزلي }
$$

r- - التخطيط لعمل الدورات التدريسية المناسبة لمعاوني أعضاء هيئة التدريس لتحسين

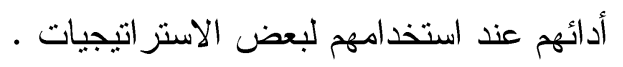

r- الإسهام في زيادة فاعلية الطلاب أثناء الدروس العملية نظر ا لاستخدام معاوني الإسي

أعضاء هيئة التذريس الاستر اتيجيات المناسبة وتطبيقها بطريقة صحيحة .

$$
\text { فروض البحث: : تتحدد فروض البحث في: }
$$

ا - توجد فروق ذات دلالة إحصائية في إجابات الطلاب على الاستبيان نزجع إلى عدم

$$
\text { تطبيق خطو ات كل إستر اتيجية بنفس الكفاءة . }
$$

r- - لا توجد فروق ذات دلالة إحصائية في إجابات الطلاب على الاستبيان المعد لقياس 


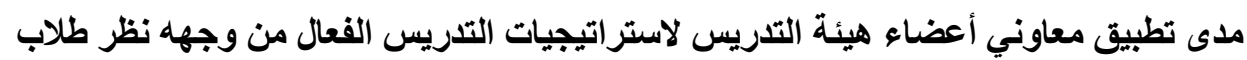
د/فاطمة عبد الرزاق عمر

\section{الاقتصاد المنزلي بكلية التربية النوعية}

مدى امتلاك معاوني أعضاء هيئة التدريس لاستر اتيجيات التدريس الفعال برجع

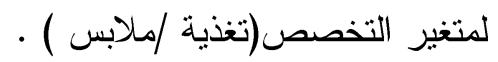

ب- ل التوجد فروق ذات دلالة إحصائية في إجابات الطلاب على الاستبيان المعد لقياس

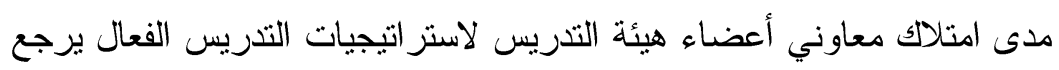

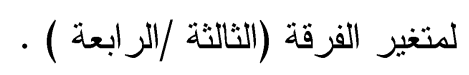

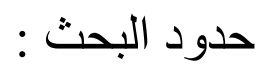

يتحدد البحث بالحدود التالية :

- - الحدود المكانية : كلية النزبية النوعية- جامعة جنوب الو ادي ل

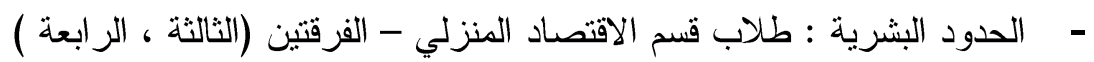

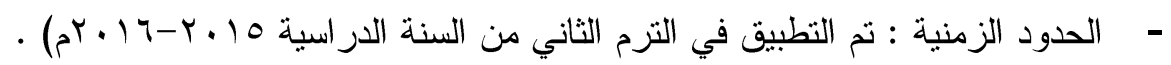

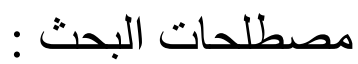

- - إستر اتيجية التدريس الفعال:

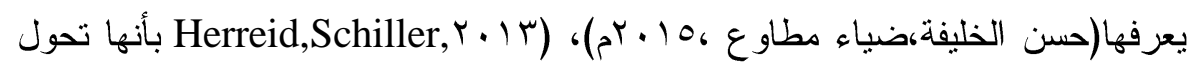
الفصل إلى ورشة تدرييية يمكن من خلالها أن يتتاقش الطلاب ما يريدون بحثـهـ و استقصــاء

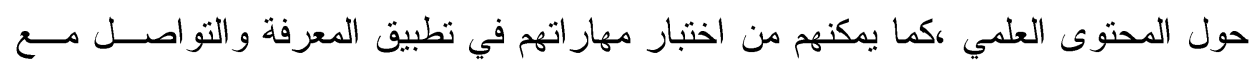

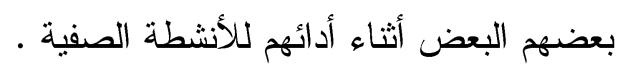

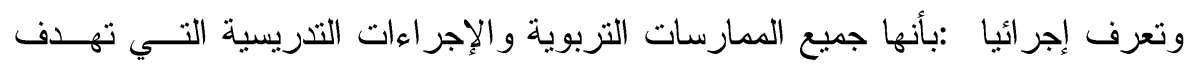

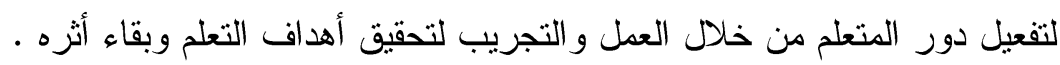

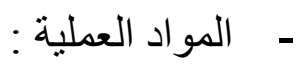

هي مو اد تشمل مجموعة من المهارات الأدائية في مجالي الاقتصـــاد المنزلـــي (تغذيـــة

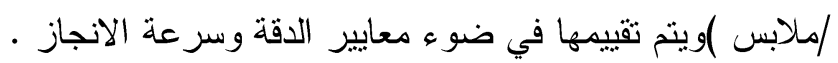

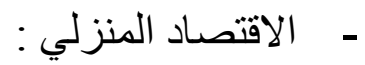

هو علم تطبيقي يهتم بالحياة الأسرية في جميع جو انبها باعتبار ها الخلية الأساسية التي

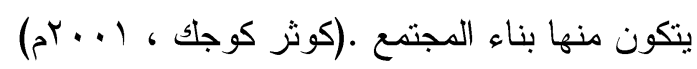

ويعرف إجر ائيا : علم تطبيقي يشمل مجالات مختلفة تهتم بنمو الأسرة لتحقيــق أهــــــافها

$$
\text { ؤون مجاتلاته ( الغذاء و التغذية /الملابس و النسيج ). }
$$




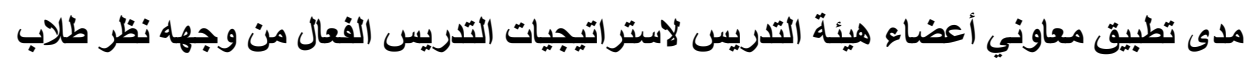
د/فاطمة عبد الرزاق عمر

\section{الاقتصاد المنزلي بكلية التربية النوعية}

$$
\text { إستر اتيجية التدريس : }
$$

هي عبارة عن إجراءات التذريس التي يخططها القائم بالتدريس مسبقا ،بحيث تعينه على التى

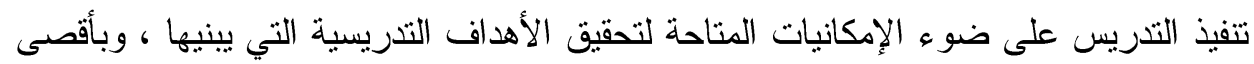

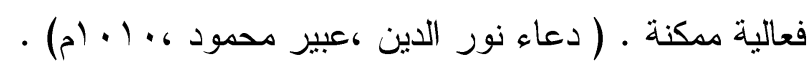
وتتحدد وتختلف استر اتيجيات التدريس فمنها استر اتيجيات تدريس تقليدية واســتراتيجيات تدريس حديثة والقائم بالتدريس (المعلم ) عليه اختيار الإستراتيجية المناسبة و إتقانها من خلال

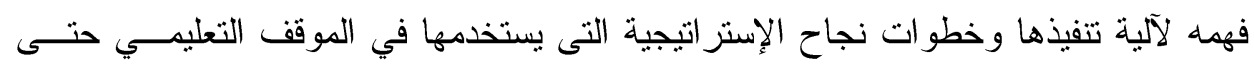

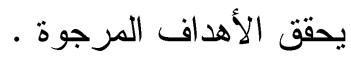

- مو اصفات الإستر اتيجية التعليمية الجيدة أن:

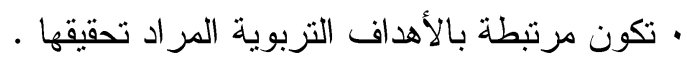

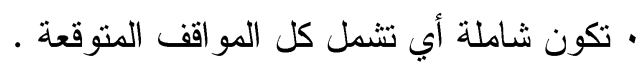

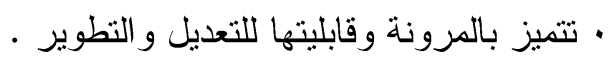

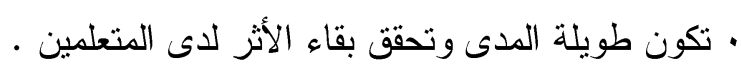
• تزيد من دافعية الطالب للتعلم بعيدا عن الملل .

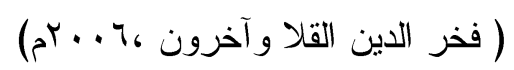

هعايير اختيار إستر اتيجية التدريس المناسبة أن:

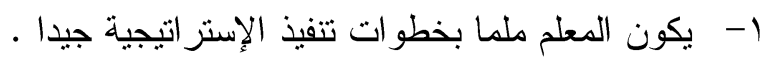

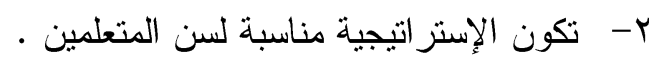

ץ- تكون الإستر اتيجية مناسبة للمادة العلمية التى سيتم تعلمها (نظرية /عملية). ع- - تكون الإستراتيجية مناسبة لأعداد المتعلمين (فردى/جماعي).

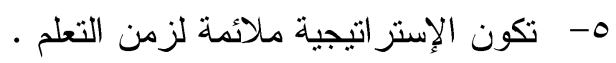

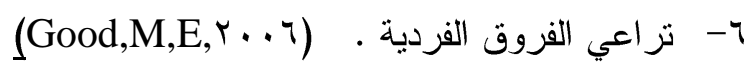

لهذا كان من الضروري أن ينقن معاوني أعضاء هيئة التدريس اختيار الإستراتيجية

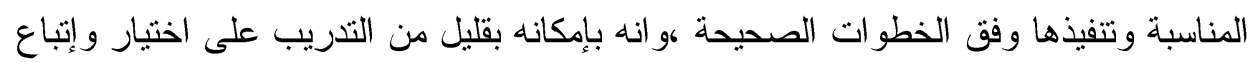

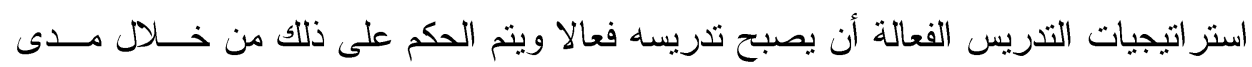

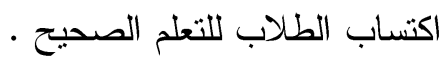

ومن الاستراتيجيات التي تم استخدامها في الدراسة هي كالتالي مع توضيح أهم مميزات كل منها : 


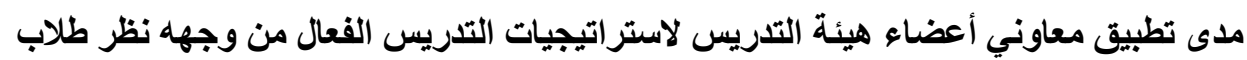
داطمة عبد الرزاق عمر

الاقتصاد المنزلي بكلية التربية النوعية الترينة

$$
\text { ا - إستر اتيجية التعلم التعاوني : }
$$

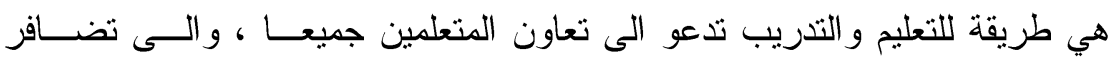

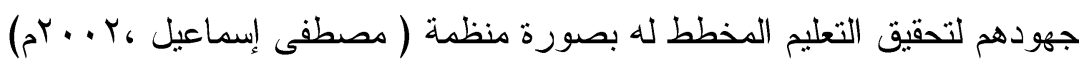
ومن مميزات التعلم التعاوني في التدريس : (Mousa Yekhlifa, r. Y V) - زيادة درجة الإتقان نتيجة تعلاون المتعلمين لانجاز المهام .

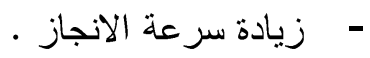

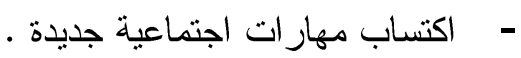

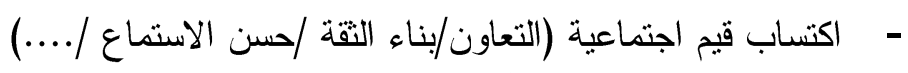

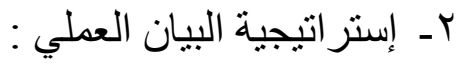

هو نشاط ندريسي يقوم به معلم الاقتصاد المنزلي (أو زائر متخصص أو طالب....)

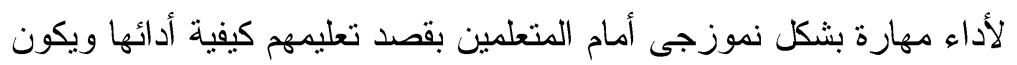

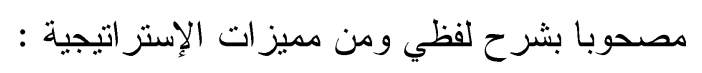

- تعتبر خبرة تعليمية مؤثرة حيث يمثل العرض نموذجا حيا للمهار ات المطلوبة.

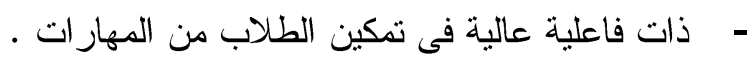

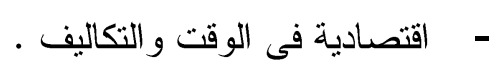

- - تدريب الطلاب على دقة الملاحظة و التعلم عن طريق المشاهدة و المشاركة.

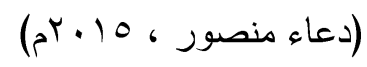

$$
\text { r- إستر اتيجية حل المشكلات: }
$$

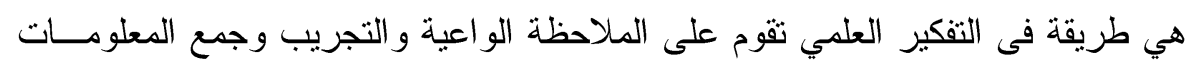

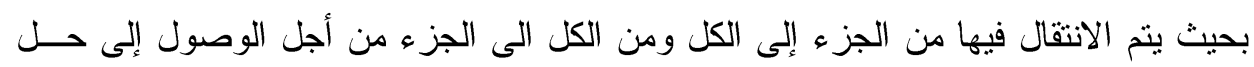

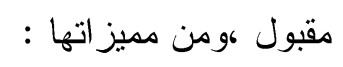

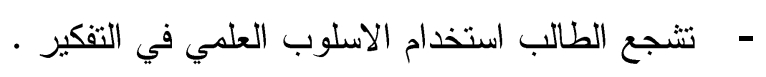

- - تجعل المتعلم يمارس دور ا جديدا يكون فعالا فيه ومنظما لخبر اته.

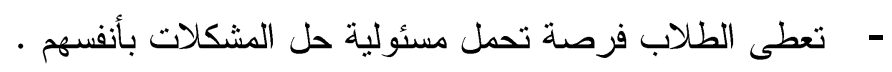

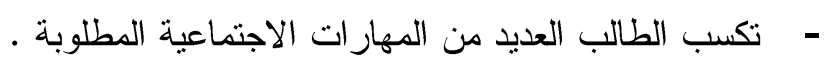

ع ـ إستر اتيجية التعلم بالاكتشاف:

هي تقنية تدريسية تشجع الطلاب على اكتثاف المفاهيم و الأفكار بنفسه وذلك عن طريق

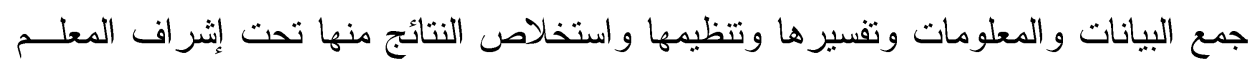




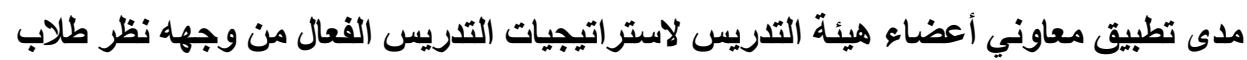
د/فاطمة عبد الرزاق عمر

\section{الاقتصاد المنزلي بكلية التربية النوعية}

$$
\begin{aligned}
& \text { الذي ينحصر دوره في التوضيح و الإرشاد دون التلقين . } \\
& \text { ومن مميز اتها هذه الإسنر اتيجية: }
\end{aligned}
$$

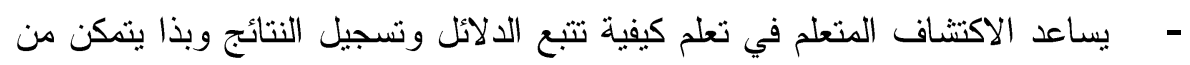

$$
\text { التعامل مع المشكلات الجديدة . }
$$

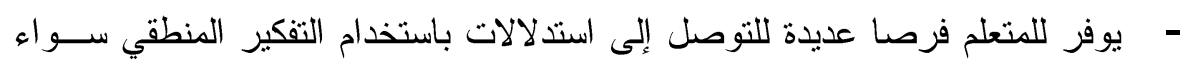

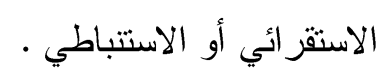

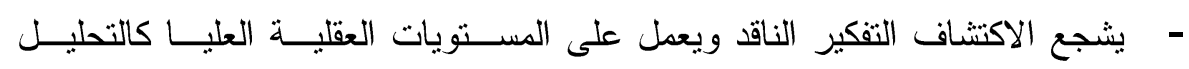

$$
\text { و التزكيب و الثقويم. }
$$

- يعوّد المتعلم على التخلص من النسليم للغير و التبعية التقليدية.

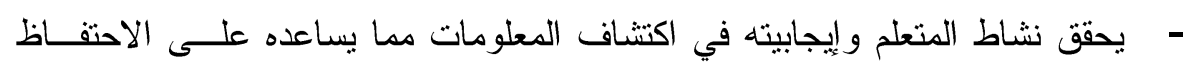
بالتعلم.

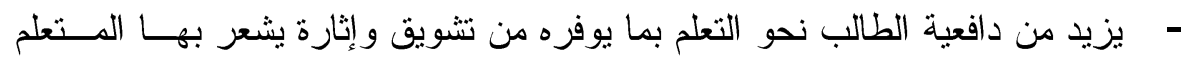

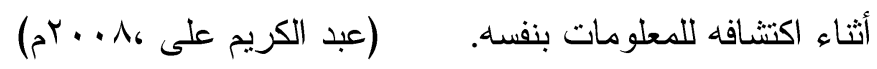

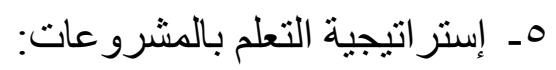

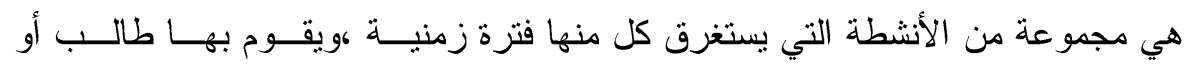

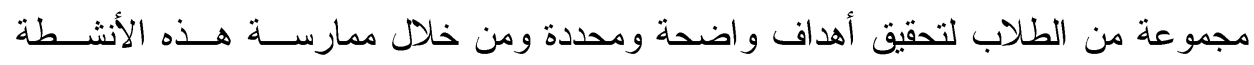

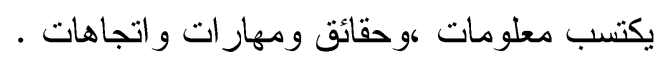

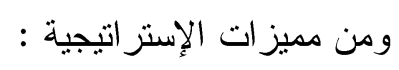

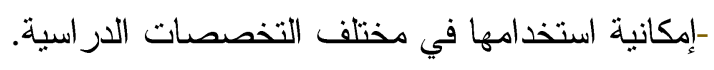

$$
\text { -تخديب الطلبة على العمل الجماعي. }
$$

-تنمي المعرفة و الخبرة و المهارة لدى الطلبة

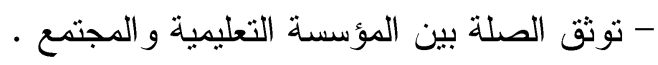
-تدريب الطلبة على التعلم الذاتي من خلال تدريبهم على البحث عن المعلومات و استغلالها بطرق مختلفة.

$$
(\mathrm{Al} \text { nesyan, } \mathrm{A}, \mathrm{r} \cdot \mathrm{I})
$$

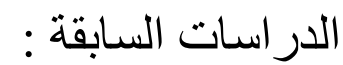

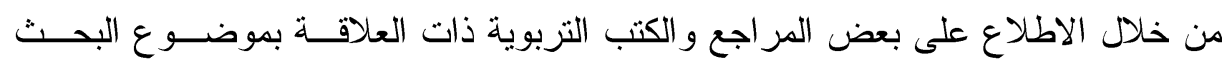

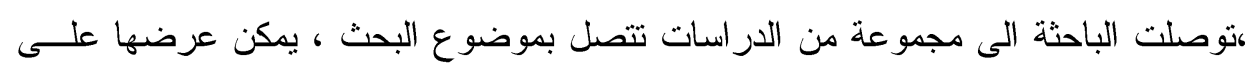




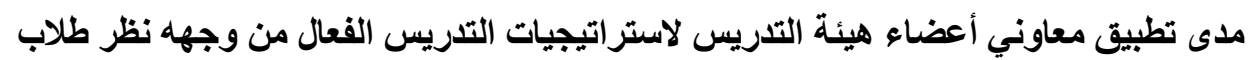
داطمة عبد الرزاق عمر

\section{الاقتصاد المنزلي بكلية التربية النوعية}

$$
\begin{aligned}
& \text { النحو التالى : }
\end{aligned}
$$

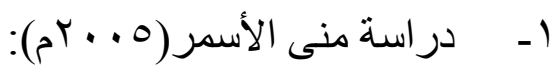

و هدفت الدراسة الى التعرف على مدى ممارسة أعضاء هيئة التدريس لكفايـات الأداء

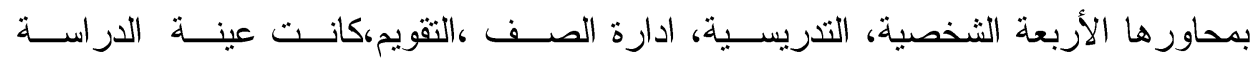

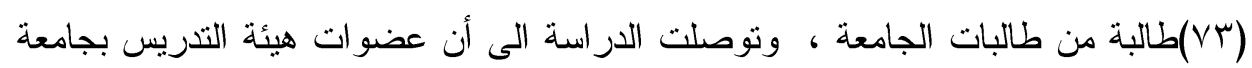

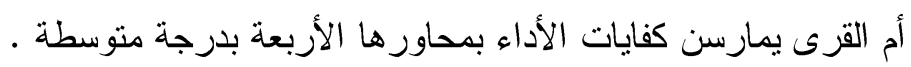

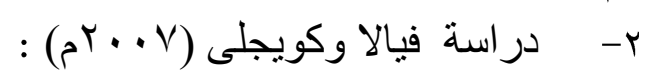

وهدفت الدراسة الى معرفة وجهات نظر طلبــة مختــارين للخصـــائص الضــرورية

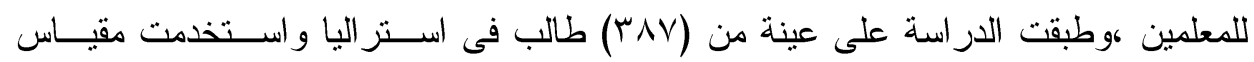

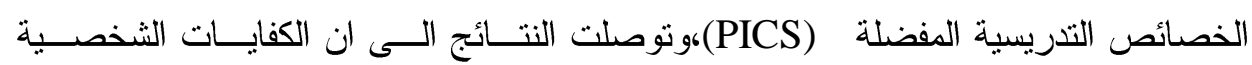

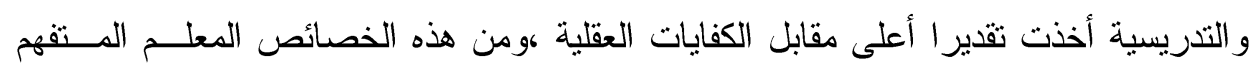

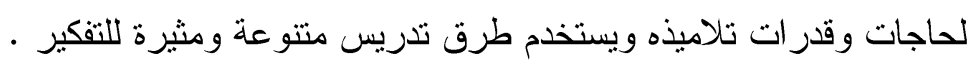

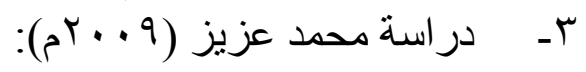

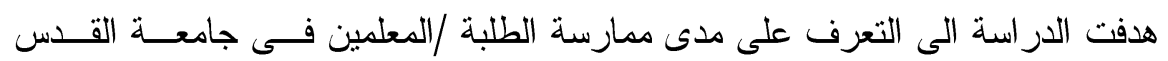

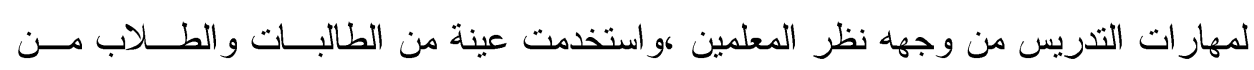

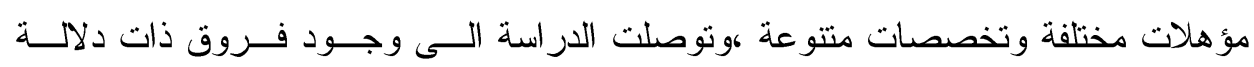

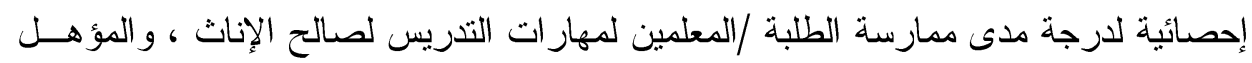

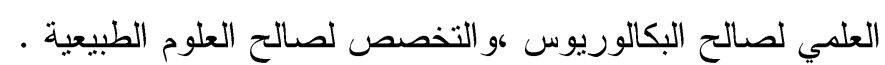

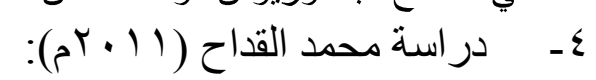

هدفت الدراسة إلى معرفة درجة إدر الك القائمين بالتدريس في الأردن بـأدوار جديــدة

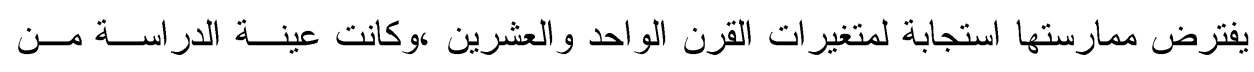

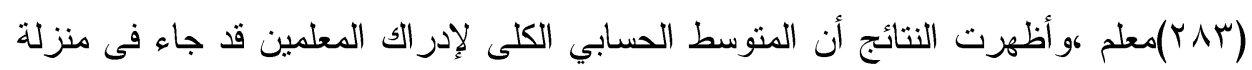

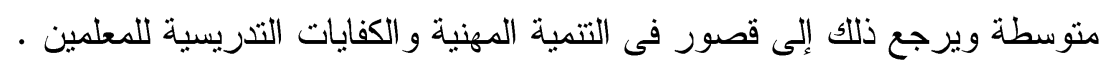
:

هدفت الدراسة الى التعرف على الكفايات المهنية للمعلمين في العالم العربي ،و استخدم

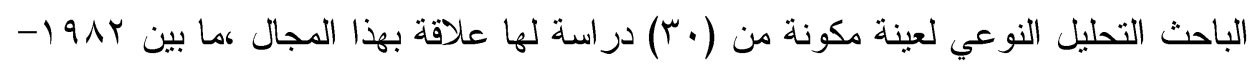

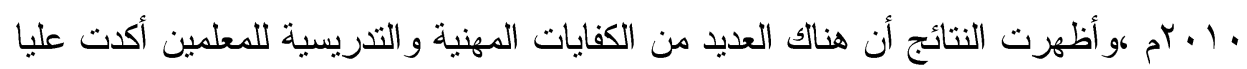
الدراسات ووضعتها في قائمة كبيرة . 


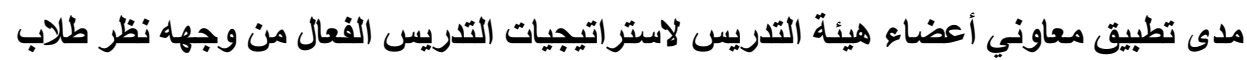
داطفمة عبد الرزاق عمر

\section{الاقتصاد المنزلي بكلية التربية النوعية}

$$
\text { التعليق على الدر اسات السابقة : }
$$

في ضوء الدر اسات السابقة يعد الاهتمام بإعداد المعلم وتأهيله أمر بالغ الأهمية لما له من تأثير على طلابه ،كما أن بعض الدر اسات تتاولت دور المعلم ووظائفه فى مجتمع ما بعد

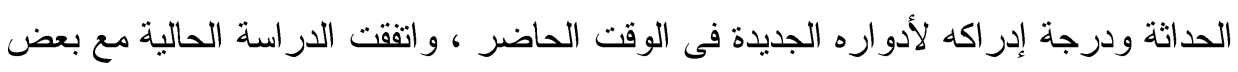
الدر اسات في نقاط : الد وند

- الاهتمام بدور المعلم وتطويره من خلال استخدامه وتطبيقه لاستر اتيجيات حديثة فى

$$
\text { • التدريس }
$$

- إعطاء فرصة للطلاب للتعبير عن وجهه نظرهم فيما يخص العملية التعليمية .

$$
\begin{aligned}
& \text { - منهج البحث ،حيث استخدمت معظم الدراسات المنهج الوصفي - } \\
& \text { - استخدام نفس أداه البحث في معظم الدراسات و هو الاستبيان . }
\end{aligned}
$$

$$
\text { واختلفت في نقاط: }
$$

- مشكلة البحث حيث اهتمت معظم الدراسات بتتمية الكفايات التدريسـية ،و الاهتمــام باستخدام استراتيجيات حديثة فى التدريس اهتم البحث الحالي لمعرفة هل يتم تطبيق

$$
\text { خطوات الاستر اتيجيات بدرجة مرتفعة . }
$$

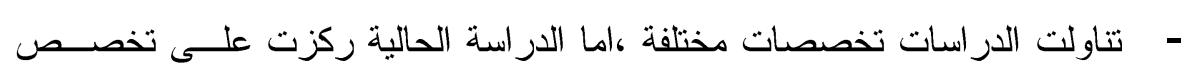

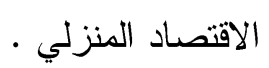

- معظم الدر اسات موجهه للمعلمين و أعضاء هيئة التذريس ،أمـــا الدراســـة الحاليــة موجها لمعاوني أعضاء هيئة التدريس. - تطبق معظم الدراسات في المو اد النظرية ،بينما الدراسة الحالية طبقت على المـــواد

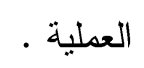

$$
\text { ثانبا : الدر اسة المبدانبة : }
$$

بعد الانتهاء من الإطار النظري للبحث ،سوف تتتاول الباحثة الدراسة الميدانية كمن

حيث أداة البحث وتحليل النتائج وتفسيرها كالتالي :

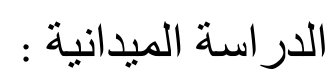

أداة البحث :وتمتلت في استبيان موجه لطلاب الاقتصاد المنزلي •

مكون من خمس محاور ،وكل محور يحتوى على تسع عبار ات .

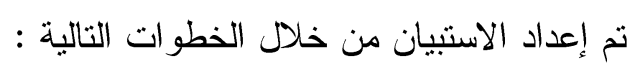

ا - الاطلاع على الكتب و المراجع المتخصصة فى استراتيجيات التدريس الحديثة . 
مدى تطبيق معاوني أعضاء هيئة التدريس لاستراتيجيات التدريس الفعال من وجهه نظر طلاب الاقتصاد المنزلي بكلية التربية النوعية التئية

\section{دافمة عبد الرزاق عمر}

r- تم صياغة عبارات الاستبيان على ان يتم توضيح خطوات تطبيق كل إستر اتيجية من

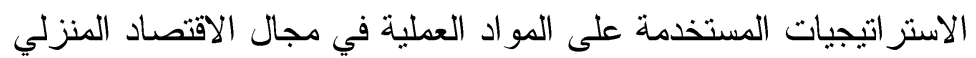

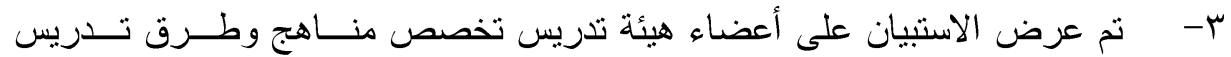

الاقتصاد المنزلي العزبان

ع-تم تعديل بعض البنود وفق آراء الأغلبية وتم حذف بعض الخطوات الى أن وصـلـل

الاستبيان إلى الصورة النهائية ـ

0- - م حساب صدق وثبات الاستبيان كالتالي :

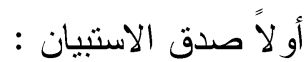

أـ أو صدق الاتساق الداخلي:

قامت الباحثة بتطبيق الاستبيان المعد لقياس مدي تطبيـق الطــلاب لاســـتراتيجيات

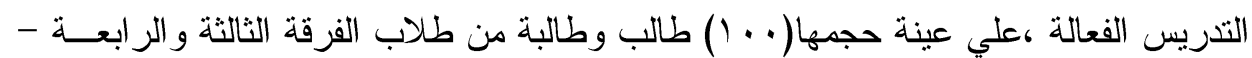

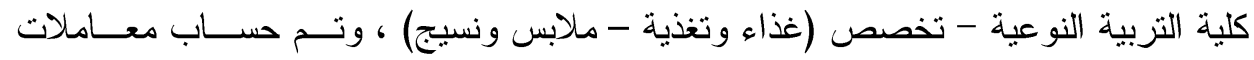

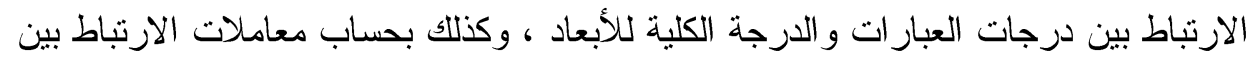

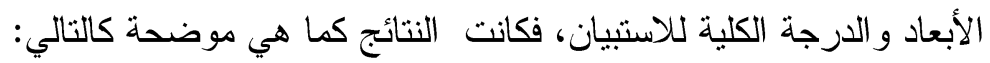

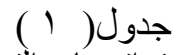

معاملات الارتباط بين درجات عبار ات الاستراتيجيات الندريس الفعالة و الدرجة الكلية للأبعاد كل بعد

\begin{tabular}{|c|c|c|c|c|c|c|c|c|c|}
\hline \multicolumn{2}{|c|}{ المشتر اتيجِية } & \multicolumn{2}{|c|}{ إستر اتيجية } & \multicolumn{2}{|c|}{ إستر اتِيجية حل } & \multicolumn{2}{|c|}{ البيتر اتِيجية } & \multicolumn{2}{|c|}{ التعلم التعاونية التيّية } \\
\hline معامل & رقم & معامل & رقم & معامل & رقم & معامل & رقم & معامل & رقم \\
\hline الارتباط & العبارة & الارتباط & العبارة & الارتباط & العبارة & الارتباط & العبارة & الارتباط & العبارة \\
\hline ***, 900 & 1 & **., $90 \mathrm{r}$ & 1 & $* * \cdot, 9 \leq r$ & 1 & ***, , ^ \ & 1 & ***, 90. & 1 \\
\hline$* * *, \wedge 90$ & r & **., 977 & r & ***, , 9 \q & r & $* *,, \wedge \vee T$ & r & ***, $\cdot \wedge r \mid$ & r \\
\hline ***.,$q \mu \mathrm{V}$ & r & ***, , $90 \mathrm{r}$ & r & ***. $90 \leqslant$ & r & *** , $9 \leq 7$ & r & ***., $9 \leq 9$ & r \\
\hline ***, , r. & $\varepsilon$ & $* *, 90$. & $\varepsilon$ & **., $9 \leqslant 9$ & $\varepsilon$ & **.,人, & $\varepsilon$ & **., 907 & $\varepsilon$ \\
\hline **., $9 \leq q$ & 0 & $* *$., $90 \varepsilon$ & 0 & $* *, 9 \leq 0$ & 0 & **., $9 \leq \varepsilon$ & 0 & ***,, $9 \cdot 7$ & 0 \\
\hline ***., $9 \leq$. & 7 & *** , $97 \mathrm{~V}$ & 7 & *** , , 97 & 7 & ***, q & 7 & ***,, $9 \leq 1$ & 7 \\
\hline ***, $\cdot \wedge 91$ & v & $* * \cdot, q \leq r$ & v & $* *, 901$ & v & $* *, \wedge) \varepsilon$ & v & **., qrV & V \\
\hline ***. , 947 & $\wedge$ & $* * \cdot, q \leq \Lambda$ & $\wedge$ & ***., $9 \leq 1$ & $\wedge$ & ***,$\wedge \wedge \vee$ & $\wedge$ & $* * \cdot, 9 \leq 7$ & $\wedge$ \\
\hline ***.,$q \cdot V$ & 9 & ***, $9 \vee T$ & 9 & ***., 971 & 9 & ***, , ^०乞 & 9 & ***., $9 \leq 7$ & 9 \\
\hline
\end{tabular}

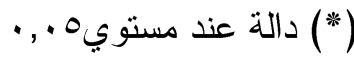

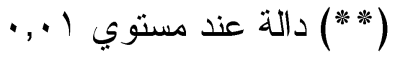

جدول(r) ( ) ( ) 


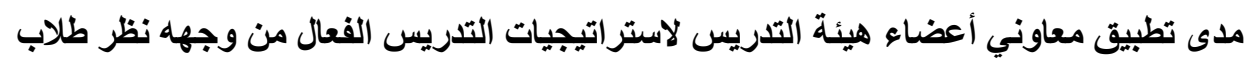

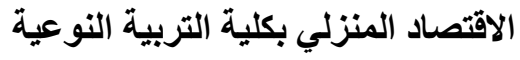

داطفمة عبد الرزاق عمر

معاملات الارتباط بين درجات الأبعاد الفرعية والدرجة الكلية للاستبيان ككل

\begin{tabular}{|c|c|}
\hline معامل الارتباط مع درجة الاستبيان ككل & الاستر اتيجية \\
\hline$* *, 9 \leq 7$ & ا- التعلم التعاوني \\
\hline$* *, 9 \leq 9$ & r- البيان العملي \\
\hline$* *, 9 \vee 1$ & س- المشرو عات \\
\hline$* *, 9 \vee 7$ & ع- حل المشكلات \\
\hline$* *, 9 \wedge 7$ & 0- الاكتشاف \\
\hline
\end{tabular}

يتضـح من جدول ( r ) السابق أن معاملات الارتبــاط بــين درجــات العبــار ات

ودرجات أبعاد الاستبيان ككل ، وكذلك معاملات الارتباط بين أبعاد الاستبيان و الدرجة الكلية

للاستبيان ككل هي معاملات ارتباط مرتفعة ودالة إحصائية عند مستوي ا •, • ، مما بؤكـــ صلاحية الاستبيان و اتساق عبار اته و أبعاده.

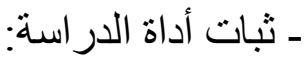

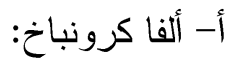

، لقياس مدي ثبات الاستبيان استخدمت ( معادلة ألفا كرونباخ)( Cronbach's Alpha ( ) حيث طبقت المعادلة على العينة الاستطلاعية ن =. م وتم التحقق من ثبات عينة الدراسة.

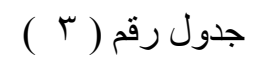

معاملات ثبات ألفا (كرونباخ) لاستر اتيجيات التدريس الفعالة

\begin{tabular}{|c|c|}
\hline معامل الثبات & الاستر اتيجية \\
\hline$* *, 9 \vee 9$ & ا- التعلم التعاوني \\
\hline$* *, 9 \vee$. & r- البيان العملي \\
\hline$* *, 9 \wedge 7$ & س- حل المشكلات \\
\hline$* *, q \wedge \wedge$ & צ- الاكتشاف \\
\hline$* *, 9 \vee 7$ & 0- المشروعات \\
\hline
\end{tabular}

يتضح من جدول ( r ) أن قيم معامل التبات مرتفعة، حيـث أن جميـع معــاملات الثبات دالة عند مستوي ا +., •، مما بؤكد أن الاستبيان الحالي وأبعاده يتميز بدرجة عالية من الثبات. 
مدى تطبيق معاوني أعضاء هيئة التدريس لاستراتيجيات التدريس الفعال من وجهه نظر طلاب الاقتصاد المنزلي بكلية التربية النوعية التئية

\section{داطمة عبد الرزاق عمر}

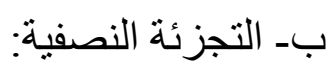

تم استخدام درجات العينة الاستطلاعية وجري معامل الثبات باستخدام التجزئة النصفية، حيث تم تجزئة درجات الأسئلة إلي نصفين واعتبرت الأسئلة ذات الأرقام الفردية هي النصف الأول والأسئلة ذات الأرقام الزوجية دي الأنئة النصف الثاني، ثم تم حساب معامل

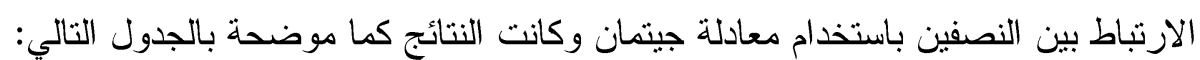

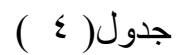

معاملات ثبات التجزئة النصفية باستخدام معادة جيتمان لأستر اتيجيات التدريس الفعالة

\begin{tabular}{|c|c|}
\hline معامل الثبات باستخدام جيتمان & استر اتيجيات التندريس الفعالة \\
\hline$*_{*}, 9 \times 1$ & التعلم التعاوني \\
\hline$* *, 9 \vee \leqslant$ & البيان العملي \\
\hline$* *, q \wedge \mu$ & حل المشكلات \\
\hline$* *, 9 \vee V$ & الاكتشاف \\
\hline 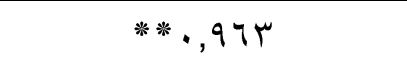 & المشروعات \\
\hline
\end{tabular}

تحليل نتائج الدر اسة وتفسير ها:

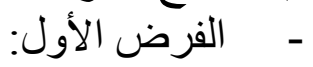

توجد فروق ذات دلالة إحصائية فى إجابات الطلاب على الاستنيان ترجـع إلـى عـدم تطبيق خطوات كل إستر اتيجية بطريقة صحيحة .

وللإجابة على هذا الفرض نم حساب المتوسط الحسابي و الانحر اف المعياري لخطــــوات كل إستر اتيجية على حدي كالتالي : جدول(0) (0)

المتوسطات و الانحر افات المعيارية لمدي تطبيق معاوني أعضاء هيئة التدريس

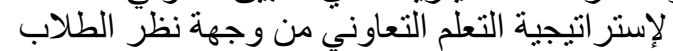

\begin{tabular}{|c|c|c|c|c|}
\hline الرتبة & 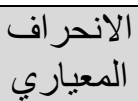 & 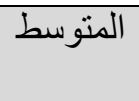 & خطوات تتفيذ الإستر اتيجية & 5 \\
\hline$\varepsilon$ & $\cdot$, Vo & $1, \mathrm{~V} V$ & تقنم التهيئة المناسبة للطلاب للتعرف علي طبيعة التعلم & 1 \\
\hline 1 & $\cdot, \Lambda \mathrm{V}$ & $r, 10$ & تقسم الطلاب إلى مجمو عات متجانسة & r \\
\hline T & $\cdot, \mathrm{V}_{1}$ & $1, \varepsilon V$ & ترتب الأماكن حتى تكون ملائمة لأسلوب التعلم & r \\
\hline
\end{tabular}




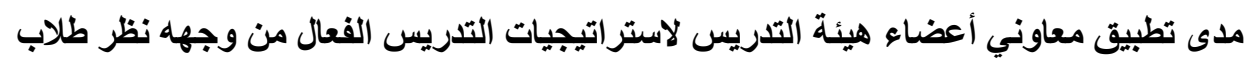
الاقتصاد المنزلي بكلية التربية النورينة التئية الترين

داطمة عبد الرزاق عمر

\begin{tabular}{|c|c|c|c|c|}
\hline 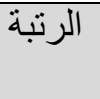 & الانحر اف المعباري & المتوسط & خطوات تتفيذ الإستر اتيجية & r \\
\hline V & $\cdot, 77$ & $1, \pi v$ & تختار طلاب كل مجمو عة علي أسس و اضحة وبعناية & $\varepsilon$ \\
\hline$\wedge$ & $\cdot, \uparrow \wedge$ & 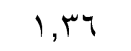 & تحدد قائد ومنسق لكل مجموعة & 0 \\
\hline r & $\cdot, \wedge 9$ & $1, \wedge$. & تشر ح الأدو ار بوضوح لكل مجمو عة & ч \\
\hline r & 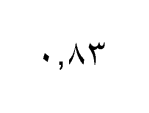 & $1, \vee \wedge$ & بالعمل. تقأكد من توفير الأدو ات و الخامات لكل مجموعة للبدء & V \\
\hline 0 & $\cdot, \vee \wedge$ & 1,79 & الر اجعة أعمال المجموعات أثثاء التنفيذ لتقديم التغذية & $\wedge$ \\
\hline 9 & $\cdot, 7 \varepsilon$ & $1, \mathrm{rq}$ & مجمو عة. تقيم العمل تقويم فردي ثم تقويم جماعي لكل & 9 \\
\hline \multicolumn{2}{|c|}{0,00} & $1 \varepsilon, 7 \wedge$ & الدرجة الكلية & \\
\hline
\end{tabular}

نلاحظ من الجدول السابق أن مــدى تطبيــق معــاونى أعضــــاء هيأـــة التــدريس

لاستر اتيجية التعلم التعاونى كانت مرتفعة حيث بلغ المتوسط الحسابى (1 T, ـ ا ) و الانحــر اف المعيارى (0,00)،جاءت نتائج نطبيق خطو ات الإستر اتيجية كالتالي :

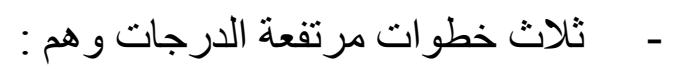

الخطوة رقم (r) وهى تقسيم الطلاب الى مجموعات متجانســة فــى الرتبــة (1)

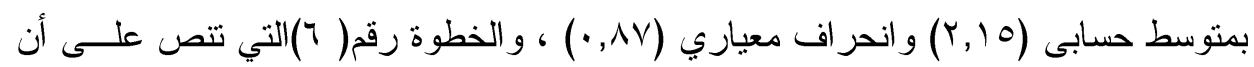
تشرح الادوار بوضوح لكل مجموعة فى الرتبــة (ب) ، حيــث بلــنغ المتوســـ الحســابى

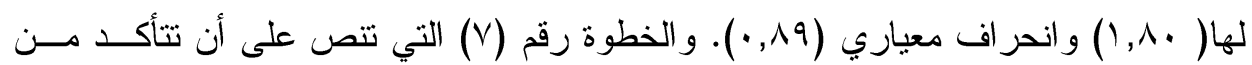

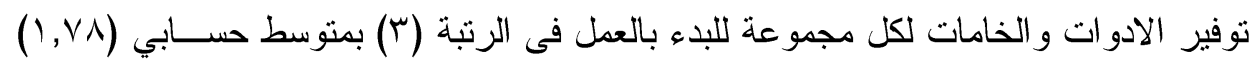
و انحر اف معيارى (r/, • ) . - ثلاث خطو ات متوسطة الدرجات و هم :

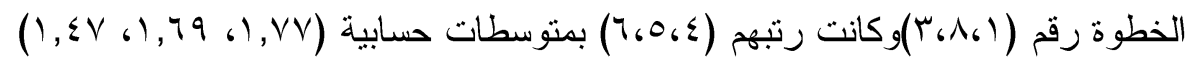

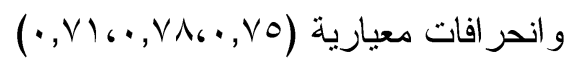
- تثلاث خطو ات منخفضة الدرجات و هم:

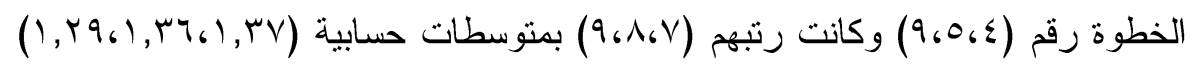

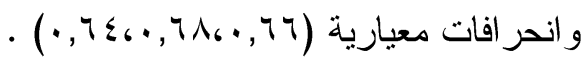




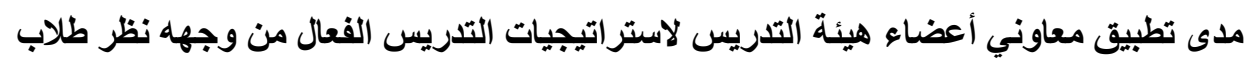

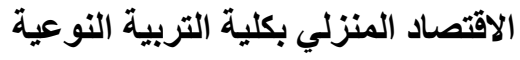

\section{داطفة عبد الرزاق عمر}

\section{جدول ( 1 ( )}

المتوسطات و الانحر افات المعيارية لمدي تطبيق معاوني أعضاء هيئة التدريس لإستر اتيجية

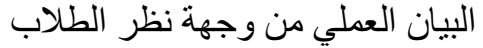

\begin{tabular}{|c|c|c|c|c|}
\hline 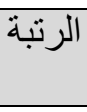 & الانحر افياري & المتوسط & خطو ات تنفيذ الاستر اتيجية & 5 \\
\hline 1 & • & $r, 17$ & تجلس المعيدة في مكان بسمح للطلاب بمشاهدتها & 1 \\
\hline r & $\cdot, \wedge \wedge$ & $1,9 \leq$ & ثقوم بأداء المهارة مع الشرح اللفظي مع الأداء. & $r$ \\
\hline$\varepsilon$ & $\cdot, \wedge$. & 1,01 & تستخدم نماذج ولوحات للشر ح عند الأداء. & r \\
\hline 9 & $\cdot, T V$ & I, & تطرح أسئلة علي الطلاب أثثاء الأداء. & $\varepsilon$ \\
\hline V & $\cdot, \vee_{0}$ & $1, \leqslant \varepsilon$ & العرض بارك الطلاب بالتتاوب فيما بينه في إجر اء & 0 \\
\hline r & חד, • & $1, r_{0}$ & تتفذ المعيدة العروض العملية بنفسها في كل مرة. & 7 \\
\hline$\wedge$ & $\cdot, \vee \wedge$ & $1, \varepsilon$. & تتنهي من أداء البيان العملي في الوقت المناسب. & V \\
\hline 0 & $\cdot, \lambda r$ & 1,00 & للقيم الأداء في النهاية و إعطاء التغذية الر اجعة & $\wedge$ \\
\hline 4 & $\cdot, 9$. & 1,07 & في البيان العملي. لترنيب الأدوات و الأجهزة المستخدمة & 9 \\
\hline \multicolumn{2}{|c|}{$0, r}$, & $1 \leqslant, r$. & \multicolumn{2}{|c|}{ الدرجة الكلية } \\
\hline
\end{tabular}

يلاحظ من الجدول السابق ان درجة تطبيق معاوني أعضاء هيئة التذريس لإســتراتيجية

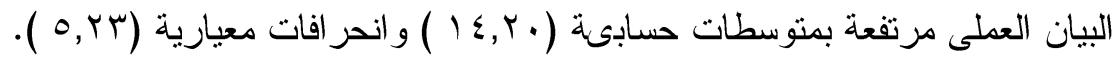
وجاءت نتائج تطبيق خطو ات الاستر اتيجية كالتالى :

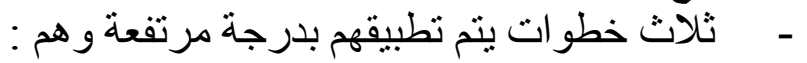

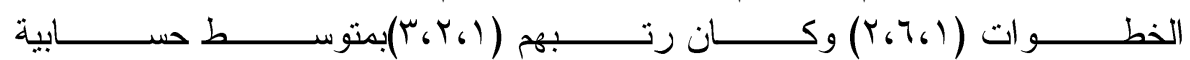

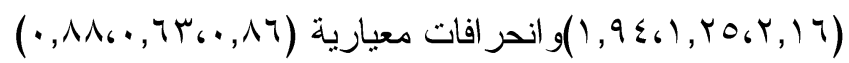

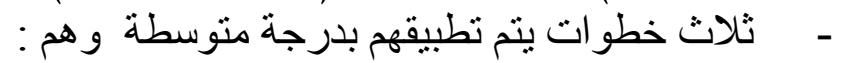

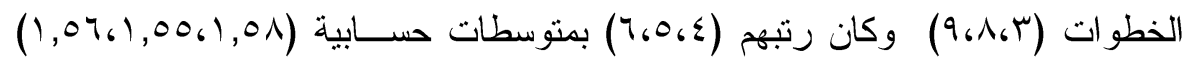

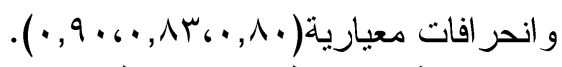

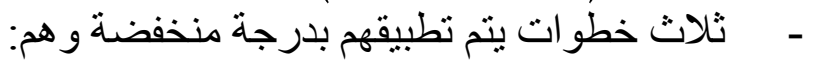

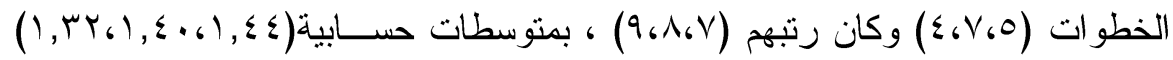

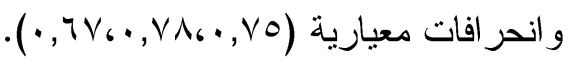
جدول (V)

المتوسطات والانحر افات المعيارية لمدي تطبيق معاوني أعضاء هيئة التدريس لإستر اتيجية حل 


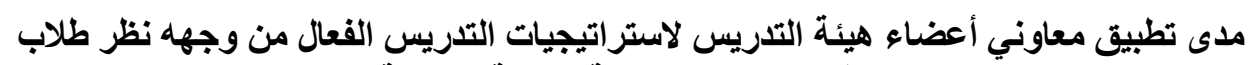
داطمة عبد الرزاق عمر

\section{الاقتصاد المنزلي بكلية التربية النوعية التربية}

\begin{tabular}{|c|c|c|c|c|}
\hline \multicolumn{5}{|c|}{ المشكلات من وجهة نظر الطلاب } \\
\hline 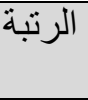 & الانحر افياري & ط المتوسد & خطو ات تنفيذ الإستر اتيجية & s \\
\hline 1 & $\cdot, 90$ & $r, \cdot \varepsilon$ & يصيغ المعيد موضو عات الدرس في صورة مشكلات. & 1 \\
\hline$\varepsilon$ & $\cdot, 91$ & $1, \wedge 7$ & له. يوضح للطلاب مالذي يريد منهم القيام بكثفه أو إيجاد حل & r \\
\hline 7 & $\cdot, \mathrm{V}$ & 1,01 & يحدد المحتوي(الإطار النظري) الخاص بالمشكلة. & r \\
\hline 9 & $\cdot, 7 \cdot$ & $1, Y_{T}$ & يوضالمشكلة. لمعيد الأهداف التعليمية و السلوكية الخاصة & $\varepsilon$ \\
\hline 0 & $\cdot, 10$ & 1,77 & يستمع المعيد للطلاب ويتلقي منهم حلول للمشكلة & 0 \\
\hline$\mu$ & $\cdot, \wedge 9$ & $1, \wedge \wedge$ & يناقش المعيد الطلاب في الحلول المقترحة للمشكلة & 7 \\
\hline$r$ & $\cdot, \wedge \vee$ & $1,9 \pi$ & يتم تطبيق الحل المناسب للمشكلة. & $\checkmark$ \\
\hline$\wedge$ & $\cdot, \uparrow \wedge$ & $1, r$ & يعطي المعيد أمثلة لمشكلات تعليمية ذات صلة بالطالب. & $\wedge$ \\
\hline V & $\cdot, \lambda r$ & $1, \leqslant 9$ & يطلب المعيد من الطلاب ذكر أمثلة من حياتهج العملية. & 9 \\
\hline & & $1 \leqslant, 97$ & الدرجة الكلية & \\
\hline
\end{tabular}

يلاحظ من الجدول السابق ان درجة تطبيق معاوني أعضاء هيئة التدريس لإستر اتيجية حل

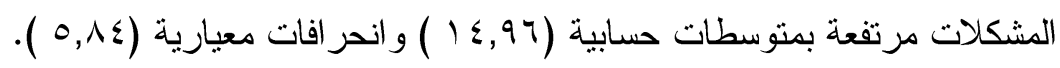

وجاءت نتائج تطبيق خطو ات الإستر اتيجية كالتالي :

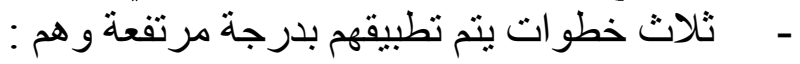
الخط

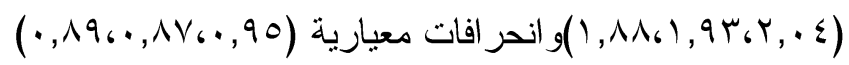

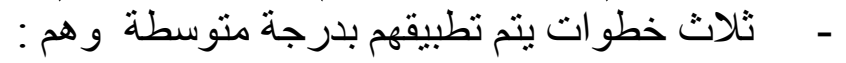

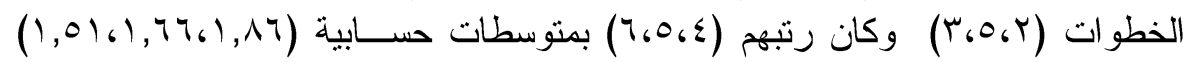

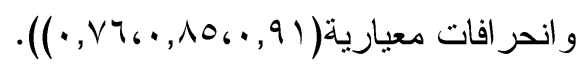

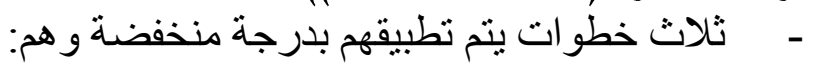

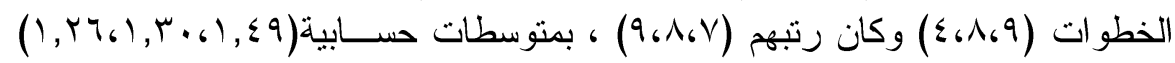

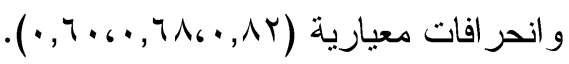

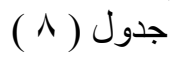

المتوسطات و الانحر افات المعيارية لمدي تطبيق معاوني أعضاء هيئة التدريس لإستر اتيجية

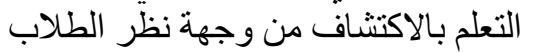




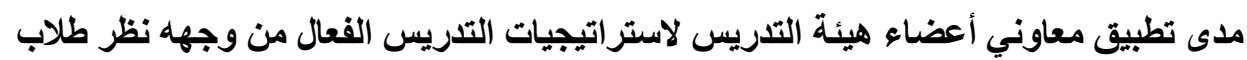
الاقتصاد المنزلي بكلية التربية النورينية النوعية

داطمة عبد الرزاق عمر

\begin{tabular}{|c|c|c|c|c|}
\hline الرتبة & الانحريار افي & المتوسط & خطوات تنفيذ الإستر اتيجية & s \\
\hline$\wedge$ & $\cdot, V \leqslant$ & $1, \leqslant \wedge$ & تعلمدها في المعيد المفاهيم العلمية والمبادئ التي سيتم & 1 \\
\hline r & $\cdot, \wedge \vee$ & $1, \wedge$ & يقوم المعيد بتحضير المواد التعليمية اللازمة لتنفيذ & r \\
\hline V & $\cdot, \wedge)$ & $1,0 \mathrm{r}$ & يصيخ المعيد المشكلة علي هيئة أسئلة فرعية تتمي & r \\
\hline r & $\cdot, 97$ & $1,9 \vee$ & يحدد النشاط أو التجربة التي سينفذها الطلاب. & $\varepsilon$ \\
\hline$\varepsilon$ & $\cdot, \lambda \mu$ & $1, \times 1$ & يحدد عمل الطلاب ودور كل منهم. & 0 \\
\hline 0 & $\cdot, \wedge \varepsilon$ & $1, V \cdot$ & يوجه المعيد الطلاب أثناء القيام بالتجربة. & 7 \\
\hline 7 & $\cdot, \wedge \vee$ & 1,79 & يستمع المعيد للطلاب أثناء تقويم التجربة. & V \\
\hline 1 & $\cdot, 94$ & $r, 1$. & يقيم المعيد الطلاب ويشرح النتائج. & $\wedge$ \\
\hline 9 & $\cdot, \vee 9$ & $1, \leqslant 0$ & مو يساعد المعيد الطلاب علي تطبيق ماتعلموه في & 9 \\
\hline \multicolumn{2}{|c|}{$\mathrm{V}, \mathrm{r}$} & 10,0 & الدرجة الكلية & \\
\hline
\end{tabular}

وجاءت نتائج تطبيق خطو ات الإستر اتيجية كالتالي : - ثلاث خطو ات يتم تطبيقهم بدرجة مرتفعة وهم : الخط

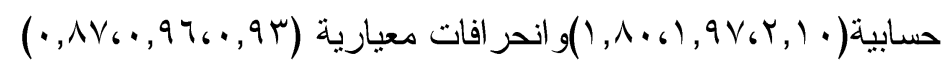
- تلاث خطو ات يتم تطبيقهم بدرجة متوسطة وهم :

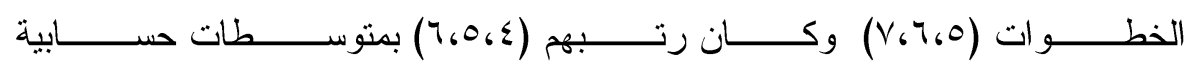

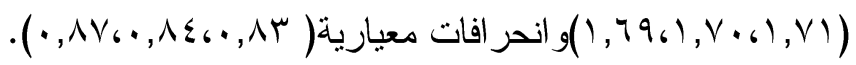
- ثلاث خطو ات يتم تطبيقهم بدرجة منخفضة وهم:

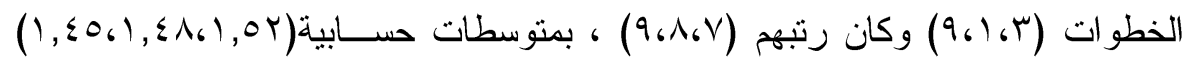
و انحر افات معيارية (1), • • • • • • • • ). 


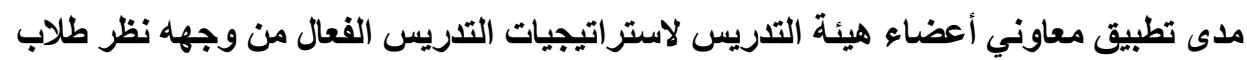
د/فاطمة عبد الرزاق عمر

\section{الاقتصاد المنزلي بكلية التربية النوعية}

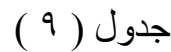

المتوسطات و الانحر افات المعيارية لمدي تطبيق معاوني أعضاء هيئة التدريس لإستر اتيجية

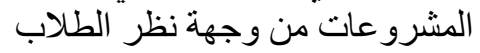

\begin{tabular}{|c|c|c|c|c|}
\hline الرتبة & الانحر افياري & المتوسط & خطوات تنفيذ الإستر اتيجية & s \\
\hline 9 & • & $1, \cdot V$ & وشتارك المعيد المعلم بمشاركة الطلاب في اختيار & 1 \\
\hline 0 & $\cdot, v_{1}$ & 1,0 & لتتعاون المعيد مع الطلاب في وضع خطة مفصلة & t \\
\hline$\Lambda$ & $\cdot, \leq r$ & $1, \cdot 1$ & لتوفر المعيد للطلاب المو اد و الخامات اللازمة & r \\
\hline r & $\cdot, \wedge r$ & 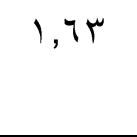 & كان مشرد المعيد دور كل طالب في المشروع سواء & $\varepsilon$ \\
\hline 7 & $\cdot,\left(V_{1}\right.$ & דוץ & خطدد المعيد ساعات محددة في الجدول لمتابعة & ○ \\
\hline 1 & $\cdot, 9 \wedge$ & $r, \cdot r$ & يحدد المعيد توقيت معين للانتهاء من المشروع. & 7 \\
\hline V & $\cdot, 7 \leq$ & $1, r \leqslant$ & 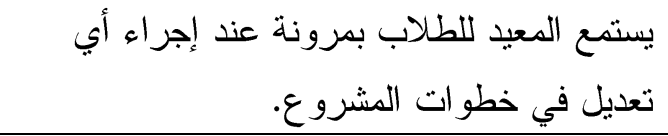 & V \\
\hline$\varepsilon$ & $\cdot, V \vee$ & $1,0 \wedge$ & للقيم المعيد المشروع وفق نقاط محددة مسبقا & $\wedge$ \\
\hline r & $\cdot, \wedge 0$ & $1, \wedge 1$ & 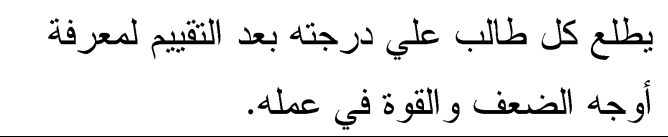 & 9 \\
\hline \multicolumn{2}{|c|}{$\varepsilon, 9 \mu$} & $1 T, \varepsilon$ & الدرجة الكلية & \\
\hline
\end{tabular}

وجاءت نتائج نطبيق خطوات الإستر اتيجية كالتالي :

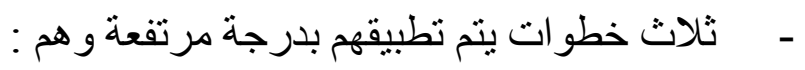

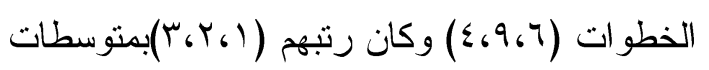

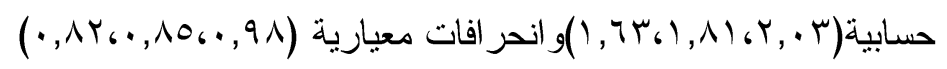
- لاث خطوات يتم تطبيقهم بدرجة منوسطة وهم : 


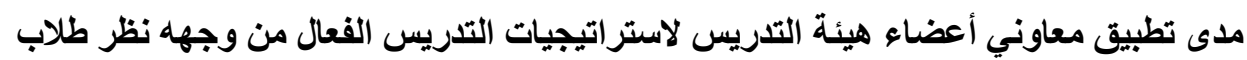
الاقتصاد المنزلي بكلية التربية النورينة التئية الترين

داطمة عبد الرزاق عمر

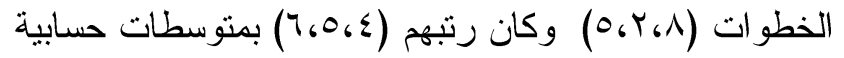

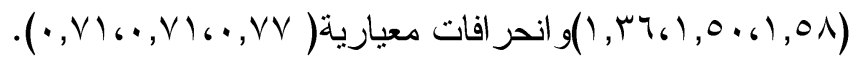

$$
\begin{aligned}
& \text { - ثلاث خطو ات يتم تطبيقهم بدرجة منخفضة وهم: }
\end{aligned}
$$

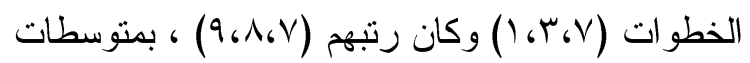

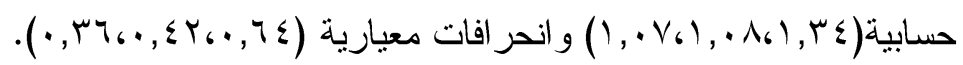

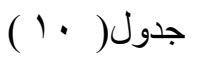

المتوسطات و الانحر افات المعيارية لمدي تطبيق معاوني أعضاء هيئة التدريس لاستر اتيجيات التدريس الفعالة

\begin{tabular}{|c|c|c|c|c|}
\hline الرتبة & الانحرياري & المتوسط & الإستر اتيجية & 5 \\
\hline r & 0,00 & $1 \leq, 71$ & التعلم التعاوني & 1 \\
\hline$\varepsilon$ & $0, r \mu$ & $1 \varepsilon, r$. & البيان العملي & $r$ \\
\hline r & $0, \wedge \varepsilon$ & $1 \leq, 97$ & حل المشكلات & r \\
\hline 1 & $v, r$ & 10,0 & الاكتشاف & $\varepsilon$ \\
\hline 0 & $\varepsilon, 9 \mu$ & $1 \mu, \varepsilon$ & المشرو عات & 0 \\
\hline
\end{tabular}

من خلال النتائج السابقة نجد أن إستر اتيجية التدريس المتبعــة( الـتـعلم التعــاوني ، البيان العملي ،حل المشكلات ،الاكتشاف ،المشروعات ) تلاقى إقبالا فـي الاســتخدام عنــد تدريس المو اد العملية في الاقتصـاد المنزلي ولكن لا يتم تطبيق جميع خطو اتها بنفس الدرجــة حيث أن معاوني أعضاء هيئة التدريس بكلية التربية النوعية قسم الاقتصاد المنزلـــي يطبـق بعض الخطو ات بدرجة جيدة وخطو ات أخرى بدرجة متوسطة و أخرى بدرجة منخفضة .

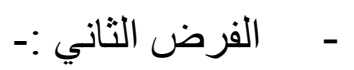

لا يوجد اختلاف في مدي استخدام معاوني أعضاء هيئة التدريس لاستر اتيجيات التدريس الفعال بين طلاب الاقتصاد المنزلي تبعا لمتغير الفرقة (الثالثة/الر ابعة). 
مدى تطبيق معاوني أعضاء هيئة التدريس لاستراتيجيات التّريس الفعال من وجهه نظر طلاب الاقتصاد المنزلي بكلية التربية النوعية التئية

د/فاطمة عبد الرزاق عمر

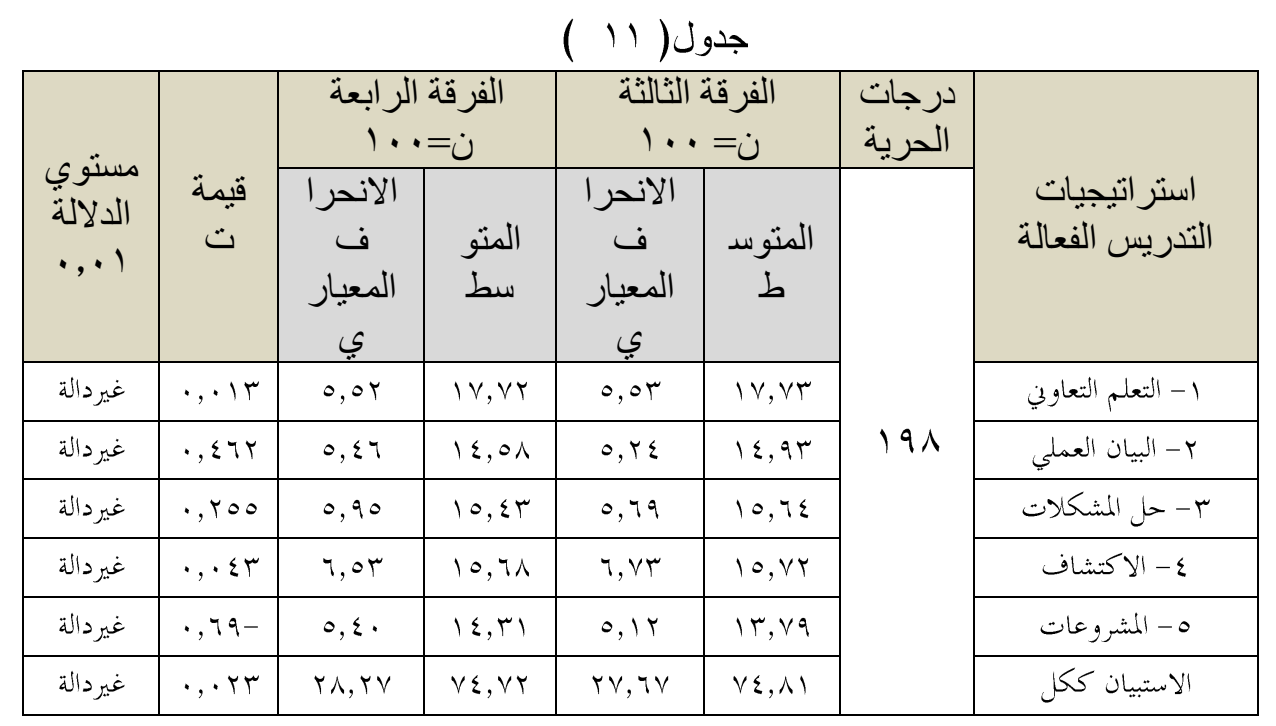

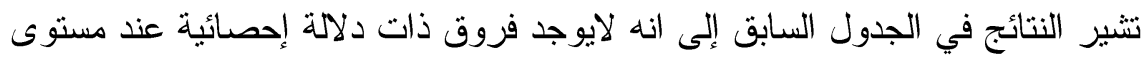

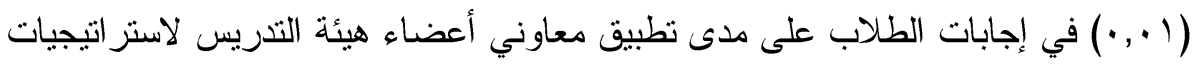

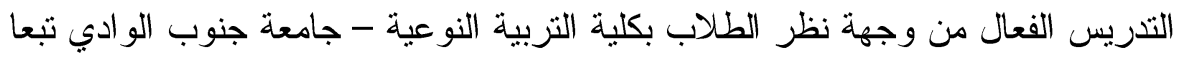

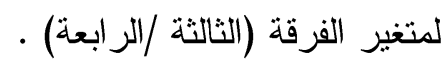

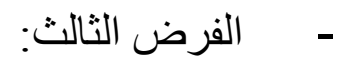

لا يوجد اختلاف في مدي تطبيق معاوني أعضاء هيئة التدريس لاستر اتيجيات التدريس الفعال

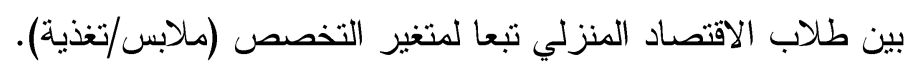

\begin{tabular}{|c|c|c|c|c|c|c|c|}
\hline \multirow[b]{2}{*}{ الدالة } & \multirow[b]{2}{*}{ تيمة } & \multicolumn{2}{|c|}{ ن=ابس } & \multicolumn{2}{|c|}{ ن تغبة 1.} & \multirow[t]{2}{*}{ الحرية } & \multirow[b]{2}{*}{ التدريس التيجيات } \\
\hline & & الانحر & سط المتو & الانحر & ط ط الوسد & & \\
\hline غيردالة & $1, \varepsilon$. & $T, K r$ & $1 \leqslant, 1 \pi$ & $\varepsilon, V 4$ & $10, Y T$ & \multirow{6}{*}{191} & 1 - التعلم التعاوي \\
\hline غيردالة & $1, \varepsilon-$ & 0,9 & $1 \varepsilon, V \pi$ & $\{, 0\}$ & $1 r, 4 V$ & & r- البيان العملي \\
\hline غيردالة & $r, I Y-$ & 4,11 & $10, \lambda r$ & $0, \sum 4$ & $1 \leqslant, .9$ & & r- حل المشكلات \\
\hline غيردالة & $\cdot, 11$ & $v, \cdot r$ & $10,0$. & $\Upsilon, \xi$. & 10,71 & & ع - الاكتشاف \\
\hline غيردالة & $\cdot, \lambda \cdot-$ & $0, Y V$ & $\mid r, 71$ & $\varepsilon, \infty \lambda$ & Ir,Ir & & ه- المشروعات \\
\hline غيردالة &., $0 Y-$ & $r \cdot, \cdot r$ & $V r, A v$ & $r_{0}, r_{\varepsilon}$ & $v 1, v q$ & & الاستبيان ككل \\
\hline
\end{tabular}




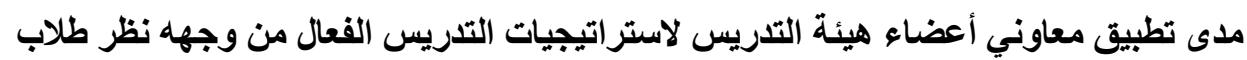
الاقتصاد المنزلي بكلية التربية التورينية التوعية الترين

داطمة عبد الرزاق عمر

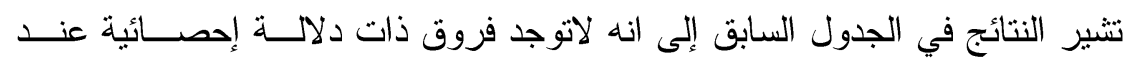

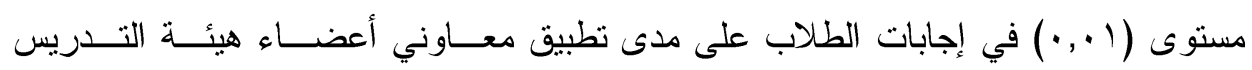

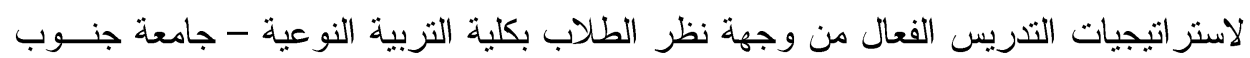
الو ادي تبعا لمتغير التخصص( تغذية / ملابس ).

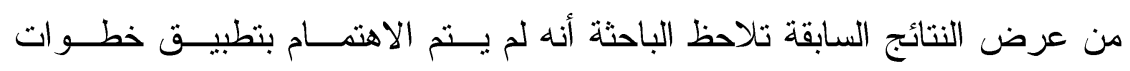
الاستر اتيجيات المستخدمة في التدريس من قبل معاوني أعضـــاء هيأـــة التـدريس بصـــورة متساوية،و انه تم الاهتمام بتطبيق بعض الخطوات بصورة جيدة وخطو ات أخـري بصــورة متوسطة،و أخرى لم يتم تطبيقها بالرغم من اهتمامهم باستخدام استر اتيجيات حديثة في تدريس

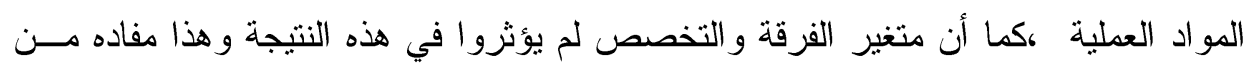
وجهة نظر الباحثة :

- - أنه ينقص معاوني أعضاء هيئة التدريس بكلية التربية النوعية بقنا التدريب الكافي

$$
\text { لاستخدامهم وتطبيقهم لخطو ات هذه الاستز اتيجيات . }
$$

- ما أن متغير الفرقة و التخصص ليس له تأثير على النتيجة فهذا يدل على أن القائم بالتدريس سو اء كان معاون أوعضو هيئة تدريس هو العنصر الأساسي والمسئول الأول عن جودة العملية التعليمية .

لذلك تري الباحثة الاهتمام ببعض النقاط التي صاغتها في صورة توصيات للبحث . توصبات البحث: من خلال النتائج السابقة يمكن عرض بعض التوصيات :

1 ـ عمل دور ات لمعاوني أعضاء هيئة التدريس في بداية تعيينهم لتدريبهم على كيفية

تطبيق بعض الاستر اتيجيات الحديثة عند تدريس المواد العملية بصورة صحيحة .

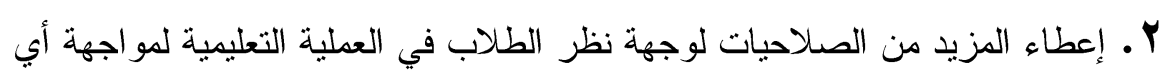
مشكلات يعانو ا منها . مطرئ. 


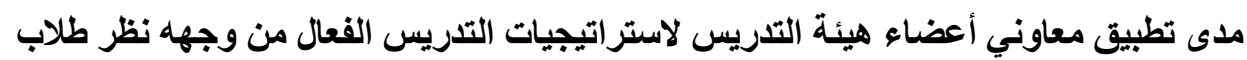
د/فاطمة عبد الرزاق عمر

$$
\text { أو المرالجع إجع العربية : }
$$

1- حسان العمارى (11 + rم) : إستر اتيجية التدريس الفعال ، دار الفكر ،اليمن ،صنعاء.

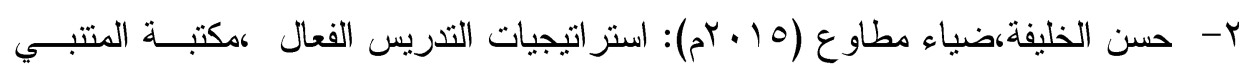
كالقاهرة .

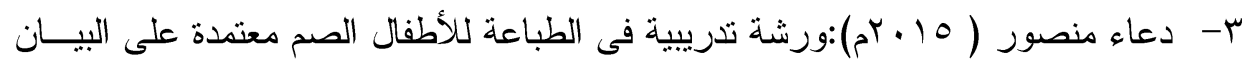

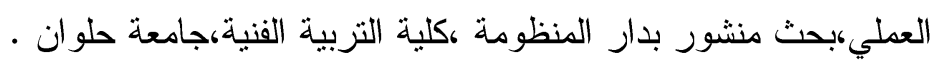

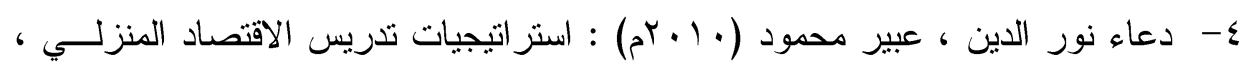

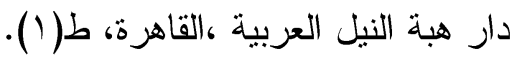

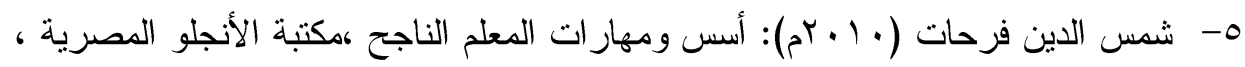
ط ا ، القاهرة .

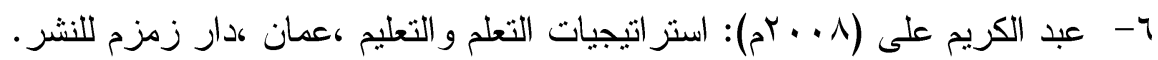

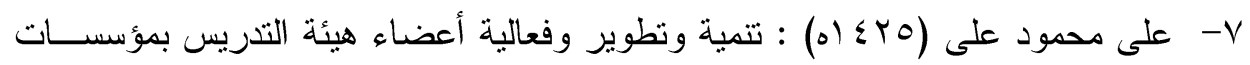
التعليم العالي ، ندوة تتمية أعضاء هيئة التدريس في مؤسسات التعليم العالي (التحديات

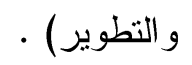

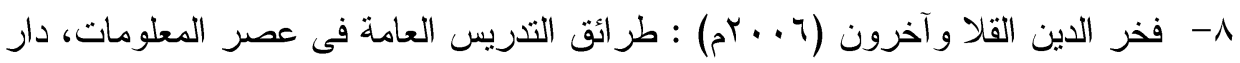

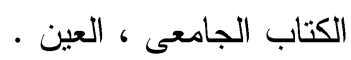

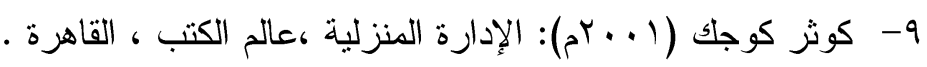

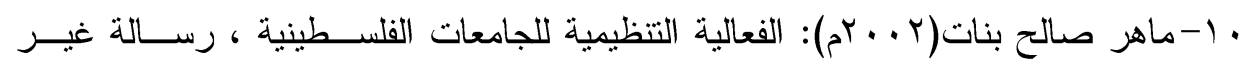

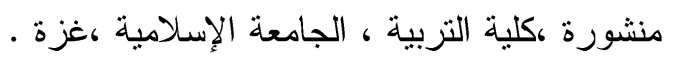

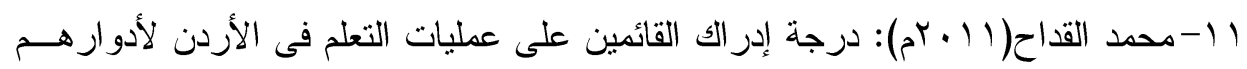

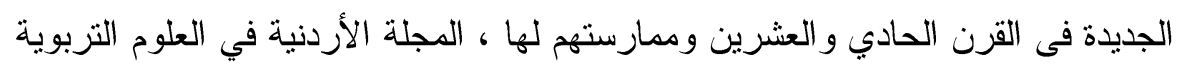

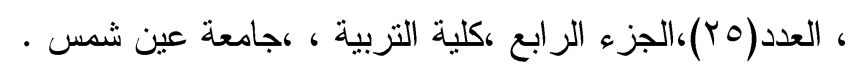

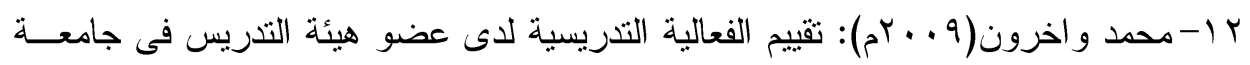

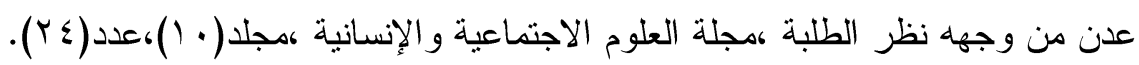

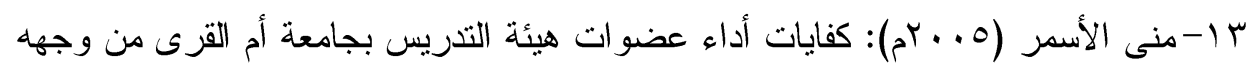

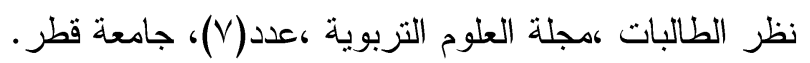

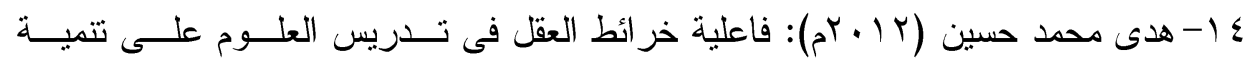

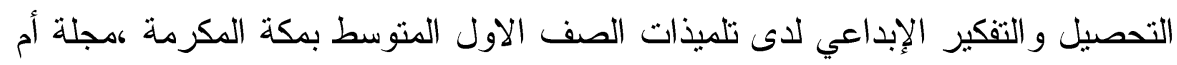

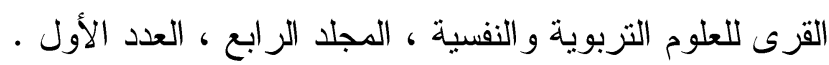


مدى تطبيق معاوني أعضاء هيئة التدريس لاستراتيجيات التدريس الفعال من وجهه نظر طلاب التاب التهاب الاقتصاد المنزلي بكلية التربية التينية النوعية التريس

داطفمة عبد الرزاق عمر

10- Al srhid, Mohammed( $Y \cdot \mid r)$ : Analytical study of the professional of the teacher in the Arab world, Journal of Education and practice,vol.r,no. 1 r.

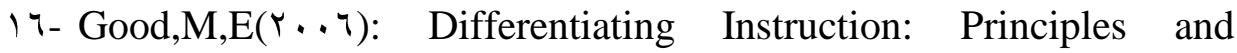
Techniques For the Elementary Grads, Masters Dissertation Dominican University PF California, San Rafael.

I $V$ - Herreid,Clyde\&Schiller,Nancy A. $(Y \cdot \mid r)$ : "Case studies and the flipped classroom "Journal of College Science Teachers Association,PP.7r.

\^- Mousa Yekhlifa( $(\cdot \mid \bigvee)$ : "Cooperative Learning Strategies Principles and Techniques" ,Global Libyan Journal ,AL-Jabal AL-Gharbi University-Bader College.

19- Al nesyan,A $(Y \cdot \mid r)$ : "Teaching and Learning Thinking Skills in the kingdom of Saudi Arabia : case studies from seven primary schools, Unpublished $\mathrm{PhD}$ Thesis, School of Education , University of Exeter,Uk.

$\Upsilon$.- Villa ,Wilma\&Quigley,Sibhan $(r \ldots \vee)$ : Selective students, Views of the Essential Characteristics of Effective Teachers.http://www.are.edu a/u $/ / r / r \cdot 1 r$. 